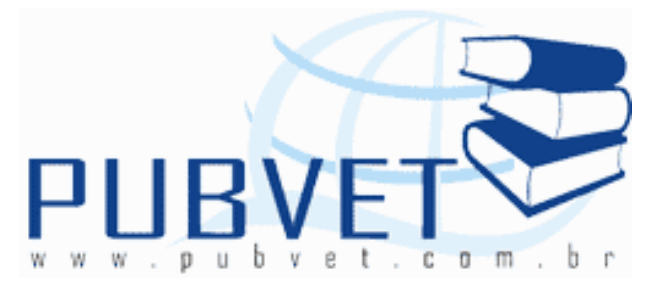

PUBVET, Publicações em Medicina Veterinária e Zootecnia.

\title{
Potencial produtivo de um grupamento genético de ovinos nativos Sulmatogrossenses
}

\section{Fernando Miranda de Vargas Junior ${ }^{1}$, Maíza Leopoldina Longo ${ }^{1}$, Leonardo de Oliveira Seno ${ }^{1}$, Guilherme dos Santos Pinto ${ }^{2}$, Marcos Barbosa-Ferreira ${ }^{3}$, Daniele Portela de Oliveira ${ }^{4}$}

${ }^{1}$ Programa de Pós-Graduação em Zootecnia - Universidade Federal da Grande Dourados. E-mail: fernandojunior@ufgd.edu.br.

${ }^{2}$ Autônomo Medico Veterinário.

${ }^{3}$ Centro de Tecnologia em Ovinocultura (CTO) Universidade Anhaguera-Uniderp ${ }^{4}$ Programa de Pós-Graduação em Zootecnia - Universidade Estadual de Maringá.

\section{Resumo}

O estado de Mato Grosso do Sul possui animais de um grupamento genético Nativo Sulmatogrossense que tem se mostrado altamente adaptado e com grande potencial produtivo e reprodutivo, esses animais apresentam uma combinação de alelos que se aproximam das raças lanadas do sul e deslanadas do nordeste, abrindo dessa forma caminho para a possibilidade da criação de uma nova raça. Os ovinos desse grupamento não apresentam estacionalidade reprodutiva podendo produzir até 1,5 cordeiros/ano. Possuem ainda o alto potencial produtivo, podendo ganhar até $350 \mathrm{~g} / \mathrm{dia}$, proporcionando dessa forma animais precoces, abatidos com até 6 meses de idade com peso de 
VARGAS JUNIOR, F.M. et al. Potencial produtivo de um grupamento genético de ovinos nativos Sulmatogrossenses. PUBVET, Londrina, V. 5, N. 30, Ed. 177, Art. 1197, 2011.

$40 \mathrm{Kg}$, podendo apresentar um rendimento de carcaça de $50 \%$. Por serem animais lanados, a lã pode ser considerada um subproduto de grande importância. Assim conservar as características desses animais é de suma importância, tanto para colaborar com a produção ovina regional, como para se oferecer uma opção a mais de raça a ser criada e utilizada em sistemas de produção de ovinos.

\title{
Productive potential of a genetic origin of native sheep Sulmatogrossenses
}

\begin{abstract}
The state of Mato Grosso do Sul has a genetic origin of animals native Sulmatogrossense that has been highly adapted and highly productive and reproductive potential, these animals exhibit a combination of alleles that are close to the south and tossed races wooless Northeast, thus paving the way for the possibility of creating a new race. The sheep of this group do not exhibit reproductive seasonality may produce up to 1.5 lambs per year. They also have high yield potential and can earn up 350 g/day, thereby providing early animals slaughtered within 6 months of age weighing $40 \mathrm{~kg}$ and may have a carcass yield of $50 \%$. Herd animals with wool, the wool can be considered a byproduct of great importance. So keep the characteristics of these animals is of paramount importance, both to collaborate with the regional sheep production, as if to offer an additional option to breed to be created and used in sheep production systems.
\end{abstract}

\section{Introdução}

Os ovinos foram introduzidos no Brasil por colonizadores europeus a partir do descobrimento. As raças inseridas no país foram primeiramente submetidas à seleção natural adaptando-se assim a ambientes diferenciados e condições 
VARGAS JUNIOR, F.M. et al. Potencial produtivo de um grupamento genético de ovinos nativos Sulmatogrossenses. PUBVET, Londrina, V. 5, N. 30, Ed. 177, Art. 1197, 2011.

edafoclimáticas adversas, sendo hoje conhecidas como animais crioulos, nativos, naturalizados ou locais (MORAIS, 2001).

O Mato Grosso do Sul possui privilegiada localização geográfica, condições climáticas favoráveis e perfil para produção de ovinos (PINTO et al., 2009). Na região, as criações de ovinos têm como objetivo principal a produção de carne, sendo que esta atividade é desenvolvida, geralmente, paralela à produção agropecuária, onde os outros produtos da ovinocultura como pele, lã e leite não são explorados comercialmente.

A falta de tradição na criação intensiva de ovinos no Estado leva à busca de animais e técnicas de produção em outras regiões do país. Verifica-se, portanto, a necessidade da utilização de animais adaptados às condições regionais de Mato Grosso do Sul, sendo necessário ainda validar e/ou ajustar os manejos às condições ambientais e regionais.

As raças ovinas naturalizadas ou nativas já identificadas se destacam pela rusticidade e capacidade de adaptação a regiões de clima semiarido, tropical e subtropical no Brasil. De acordo com Gomes et al. (2007) o grupamento genético de ovinos Nativos Sulmatogrossenses, dentre os exemplares avaliados, apresentam uma combinação de alelos que se aproximam das raças lanadas do sul e deslanadas do nordeste, o que indica variabilidade genética e abre caminho para a possibilidade da criação de uma nova raça.

Todavia, para o desenvolvimento de uma nova raça, com base cientifica, é necessário o conhecimento acerca das características de desempenho zootécnico do material genético disponível. Assim, há a necessidade de nos ovinos nativos Sulmatogrossense estudar possíveis características a serem utilizadas como critério de seleção em programas de melhoramento com a finalidade de obter animais com maior peso ao desmame visando menor período de terminação em confinamento ou a pasto.

De acordo com Egito et al. (2002) é fundamental a estruturação de programas de preservação e conservação dos grupos genéticos naturalizados, com intuito de utilização destes no sistema produtivo, agregando características de adaptação, que normalmente são de baixa herdabilidade e 
conseqüentemente pequena resposta à seleção. Para a condução do programa de melhoramento deste grupamento genético é indispensável à escrituração zootécnica do rebanho pelos produtores.

No entanto, o desconhecimento do potencial produtivo destes animais faz com que venham ocorrendo cruzamentos indiscriminados desses animais com raças exóticas, acarretando em perda destas características selecionadas naturalmente ao longo dos anos.

\section{Características do grupamento genético}

No ano de 2005, foi iniciado um estudo exploratório por pesquisadores da UNIDERP - CTO, EMBRAPA, UFMS e posteriormente a UFGD, afim de identificar e manter o grupamento genético. A principio foram adquiridos 300 animais "pantaneiros" (Figura 1) de criatórios do alto e baixo pantanal sulmatogrossense, os quais apresentavam características fenotípicas semelhantes entre si, mas distante dos padrões genotípicos das raças exóticas criadas no Brasil. Esses animais são encontrados em grande quantidade em fazendas isoladas na região, vivendo há anos sob qualquer tipo de seleção ou melhoramento genético, fato este que possibilita concluir que esses ovinos são adaptados à região sulmatogrossense.
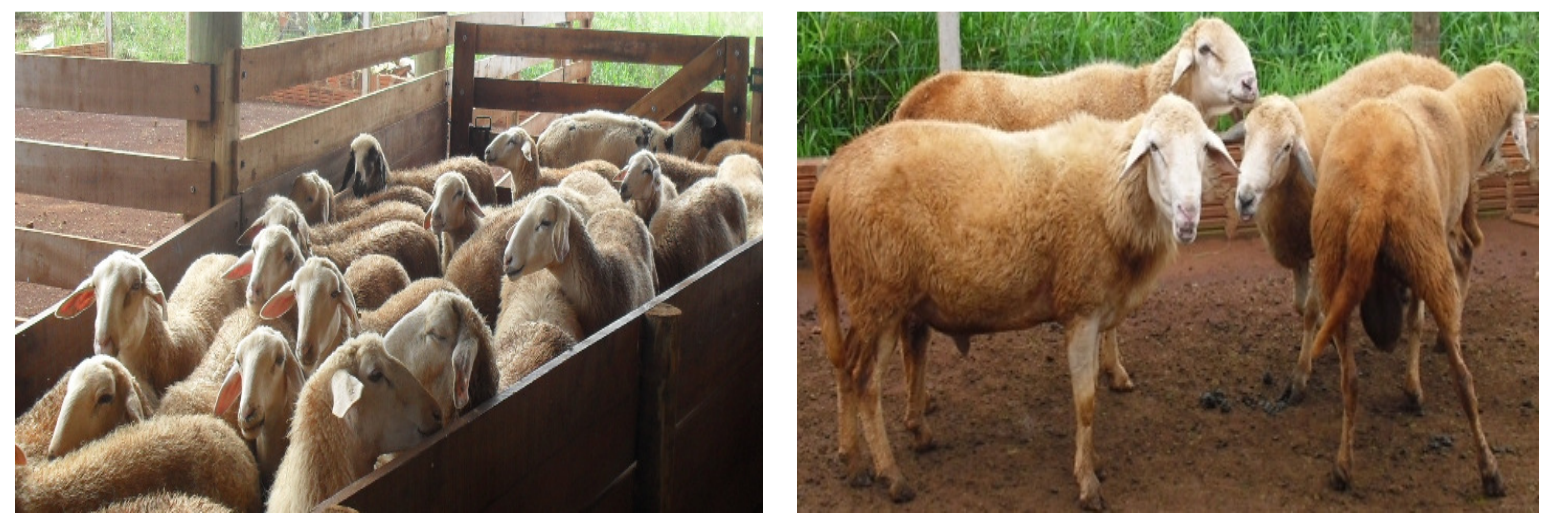

Figura 1 - Ovinos do Grupo Genético Nativo Sulmatogrossense. À esquerda ovelhas e à direita os carneiros. 
VARGAS JUNIOR, F.M. et al. Potencial produtivo de um grupamento genético de ovinos nativos Sulmatogrossenses. PUBVET, Londrina, V. 5, N. 30, Ed. 177, Art. 1197, 2011.

No aspecto reprodutivo os animais do grupamento genético nativo Sulmatogrossense apresentam características que merecem destaque, pois apresentam comportamento reprodutivo distinto ao da maioria das raças ovinas criadas no país, as quais permitem a produção de apenas um cordeiro por ano, no sistema tradicional ou 1,5 cordeiros por ano em sistemas mais tecnificados. Diferentemente, em estudos realizados por Martins, et al. (2008) foram identificados que as fêmeas Nativas Sulmatrogrossenses possuem desempenhos cíclicos e fertilidade favorável durante a época de adversidade de fotoperíodo, não apresentando dessa forma estacionalidade reprodutiva, favorecendo a produção de cordeiros durante o ano.

Nos reprodutores (carneiros) estas variações se alteram substancialmente em função da raça e demonstram a sensibilidade de cada animal ou grupo genético para fatores ambientais. Em regiões tropicais, no entanto, onde o fotoperíodo varia muito pouco, não se evidencia forte estacionalidade reprodutiva.

Embora os carneiros produzam sêmen o ano todo, um período de "esterilidade" ou reduzida eficiência reprodutiva ocorrerá por vários meses (DUTT, 1960). A estacionalidade reprodutiva nos carneiros pode ser um fator limitante à produção constante durante $\mathrm{o}$ ano e em larga escala, pois impossibilita o cruzamento industrial, para obtenção de cordeiros precoces e com características de carcaça satisfatórias.

Miazzi et al. (2008 e 2009) demonstraram que tanto carneiros Nativo Pantaneiro Sulmatogrossenses jovens quanto os adultos, apresentaram performance reprodutiva semelhante e constante, salientando-se a ausência de supressão no período de maior luminosidade e que também não foram observadas variações sazonais na rotina do teste da libido destes, assim como também não houveram variações significantes na qualidades seminal durante o ano.

Estes estudos qualificam os ovinos nativos sulmatogrossenses a serem incluídos em sistemas intensivos de produção de cordeiros para corte, pois a ausência de fotoperiodismo reprodutivo permite que haja produção constante 
VARGAS JUNIOR, F.M. et al. Potencial produtivo de um grupamento genético de ovinos nativos Sulmatogrossenses. PUBVET, Londrina, V. 5, N. 30, Ed. 177, Art. 1197, 2011.

nas distintas estações do ano, diferentemente de animais lanados de origem européia.

Os Cordeiros Nativos Sulmatogrossenses nascem com peso vivo entre 2,5 e 3,5Kg em média, fato este que favorece muito a baixa incidência de partos distócicos, pois quando comparado com o peso ao nascer das demais raças estes são bastante inferiores.

Embora 0 peso ao nascer possa ser considerado inferior comparativamente, o desenvolvimento subseqüente dos cordeiros deste grupo genético é bastante satisfatório conforme demonstrado por Pinto et al. (2009), e Lima et al. (2008). O ganho de peso médio diário, em confinamento oscilou de 200 a 350 gramas por dia, dependendo do nível nutricional da dieta, este fato proporciona a produção de cordeiros precoces sendo abatidos com idade entre 4 e 8 meses, com peso vivo entre 30 e $40 \mathrm{~kg}$ apresentando alto rendimento de carcaça oscilando entre $45 \%$ e 50\%. Outro importante aspecto a ser destacado é que machos e fêmeas apresentam desempenho e produção semelhante, bem como acabamento de carcaça uniforme.

Os ovinos nativos sulmatogrossenses, oferecem ainda como subproduto a lã, esse é um importante co-produto da ovinocultura de corte no MS. Em algumas raças especializadas este produto é bastante valorizado, devido à sua qualidade superior. Apesar de não ser ideal para vestuário, a lã deste Grupo Genético pode ser utilizada para trabalhos artesanais como tapetes, baixeiros, mantas entre outros produtos (BRAUNER, 2010), o que tem boa aceitação e comércio em regiões tradicionais em bovinocultura de corte, haja vista que os produtos têxteis oriundos da lã e couro ovinos são utilizados em montarias e apetrechos de fazenda para a lida de peões com o gado e outros animais de produção.

\section{Conclusão}

Os ovinos do grupamento genético Nativo Sulmatogrossense apresentam grande capacidade produtiva e reprodutiva. Portanto, conservar as 
VARGAS JUNIOR, F.M. et al. Potencial produtivo de um grupamento genético de ovinos nativos Sulmatogrossenses. PUBVET, Londrina, V. 5, N. 30, Ed. 177, Art. 1197, 2011.

características desses animais é de suma importância, tanto para colaborar com a produção ovina regional, como para se oferecer uma opção a mais de raça a ser criada e utilizada em sistemas de produção de ovinos.

\section{Referências Bibliográficas}

BRAUNER, R. A.; Avaliação da lã de ovinos do grupo genético Nativo Pantaneiro. 2010 42p. Dissertação (Mestrado em Produção e Gestão Agroindustrial) - Universidade Anhanguera UNIDERP, Campo Grande, 2010.

DUTT, R. H.; Temperature and light as factors in reproduction among farm animals. Journal of Dairy Sciences. v.43, pp.123-144 (suppl.), 1960.

EGITO, A.A.; MARIANTE, A.S.; ALBUQUERQUE, M.S.M. Programa brasileiro de conservação de recursos genéticos animais. Archivos de Zootecnia, v.51, p.39-52, 2002.

GOMES, W. S. et al. Origem e Diversidade Genética da Ovelha Crioula do Pantanal, Brasil. In: SIMPOSIO DE RECURSOS GENÉTICOS PARA AMÉRICA LATINA Y EL CARIBE. Universidad Autónoma Chapingo, Chapingo, México. p.322, 2007.

LIMA, M.C.; VARGAS JUNIOR, F.M.; MARTINS, C.F. et al. Medidas morfométricas e rendimento de cortes da carcaça de cordeiros nativos sulmatogrossenses alimentados com dieta $100 \%$. In: ASSOCIAÇÃO BRASILEIRA DE ZOOTECNISTAS, 2008, João Pessoa. Anais... João Pessoa: Zootec, 2008. (CD-ROM).

MARTINS, C.F.; VARGAS JUNIOR, F.M.; SANTIAGO FILHO, A. et al. Aspectos reprodutivos da ovelha nativa Sul-Mato-Grossense. In: REUNIÃO ANUAL DA SOCIEDADE BRASILEIRA DE ZOOTECNIA, 45, 2008, Lavras. Anais... Lavras: SBZ, 2008. (CD-ROM).

MIAZZI, C.; BARBOSA-FERREIRA, M.; MARTINS, C. F; et al.Característica Reprodutiva De Carneiros Nativo Pantaneiro Em Mato Grosso Do Sul - Análise Do Ejaculado Seminal. In: $4^{\circ}$ Seminário interno de Iniciação científica e $2^{\circ}$ Encontro de Pós Graduação Strictu Sensu, 2009, Campo Grande, MS. Anais... do 40 Seminário interno de Iniciação científica e $2^{\circ}$ Encontro de Pós Graduação Strictu Sensu da Universidade Anhanguera-Uniderp, 2009. v.1.

MIAZZI, C.; Comportamento Sexual de Carneiros Nativos Pantaneiros em Mato Grosso Do Sul 2008

MORAIS, O. R. O melhoramento genético dos ovinos no Brasil. In: Melhoramento genético aplicado à produção animal. Ed. Pereira, J. C. C., 3ed., Belo Horizonte, FEPMUZ Editora, 2001, 555p.

PINTO, G. S. Avaliação quantitativa da carcaça de cordeiros filhos de ovelha pantaneiras acasaladas com diferentes carneiros, Santa Inês e Texel. 2009. 52 p. Dissertação (Mestrado em Produção e Gestão Agroindustrial) - Universidade Anhanguera UNIDERP, Campo Grande, 2009. 